\title{
Motor Development of Egyptian Children on the Peabody Developmental Motor Scales-2
}

\author{
Faten Abdelazeim*1, Amany Mousa ${ }^{2}$ and Shimaa Mohamed Refaat ${ }^{1}$ \\ ${ }^{1}$ Faculty of Physical Therapy, Cairo University, Egypt \\ ${ }^{2}$ Institute of Statistical Studies and Research, Cairo University, Egypt
}

Submission: August 18, 2016; Published: November 09, 2016

*Corresponding author: Faten Abdelazeim, Faculty of Physical Therapy, Cairo University, 14 Elzyat street, Giza, Egypt, Tel: 01004103219

\begin{abstract}
Background: Peabody developmental motor scale (PDMA-2) is considered one of the most commonly used tests to assess motor development in preschool children. It provide useful and comprehensive information for early assessment. It remains unclear if the standard measured established and currently used are applicable to Egyptian children.

Objectives: To establish normative data for fine motor developmental skills that can be applicable to Egyptian children.

Methods: 195 Egyptian children attending nursery schools in Greater Cairo, throughout Egypt were randomly identified, based on their chronological age (from 36 to 42 months). Each child needed to achieve a screening score of at least $80 \%$ using the Portage Scale to participate in this study. If eligible, and consent was obtained, each child was subsequently evaluated monthly using the PDMS-2 for six months, longitudinally.

Results: There are significant differences for measured subtest items of fine motor development for Egyptian children when compared with the currently available PDMA-2 normative data, using Z-scores.

Conclusion: Confirmation and acknowledgement of the differences which may exist among children from Egypt vs. those used to establish "normative standards" for diagnostic tools, such as the PDMA-2, illustrates the importance of establishing a range of different "normative values" as needed, so developmental tests, such as these, can be applicable to a wider range of geographic areas, globally. Development of standard measures of motor development for Egyptian children is needed, so as to serve as a national reference for all health care staff working in pediatric physical therapy.
\end{abstract}

Keywords: Egyptian children; fine motor development; portage scale; Peabody Developmental motor scale

\section{Introduction}

The field of study concerned with the description and explanation of changes in motor performance and motor control, across the life span, is typically called motor development. While the study of motor development has historically focused on the period from conception through to adolescence, and the changes and stages through which the developing human progresses in attaining adult levels of motor performance, researchers in this field are now also increasingly interested in the deterioration of motor skills apparent in the elderly population. Such a broadened focus is important given aging populations worldwide and given that many changes in the performance and control of motor skills are age related and occur throughout the entire life span [1].
Children are the biggest promise for the nation's future. The family, community, and government are responsible for their survival, development, and protection. The Egyptian government took successful steps in saving children' life through promoting diarrheal disease control, vaccination and Integrated Management of Childhood Illnesses (IMCI). It now focuses on child development programs aiming creation a more physically and mentally productive generation. The long term progress of any nation depends on how much it cares about its children [2].

Fine motor skills are the collective performances that involve the hands and fingers. That is, fine motor skills are those 
performances that require the small muscles of the hand to work together to perform precise and refined movements. Fine motor skills typically develop in a reasonably consistent and predictable pattern in the early years of childhood (from birth through to mid primary school). They include reaching, grasping, manipulating objects \& using different tools like crayons \& scissors. But because tasks such as printing, coloring \& cutting are not emphasized until a child is of preschool age, fine motor skill development is frequently overlooked when the child is an infant or toddler [3].

The Peabody Developmental Motor Scales-2 (PDMS-2) is the most commonly used pediatric motor outcome measurement tool. The PDMS-2 was designed to assess motor development in children from birth to 72 months of age to measure fine and gross motor skills. The possible uses of the PDMS-2 include; Determination of motor competency relative to a normative peer sample, assessment of qualitative and quantitative capacities of individual gross motor and fine motor skills, evaluation of progress over time and determination of efficacy of interventions in research [4].

The motor development of children is a critical developmental and an important area for scientific research. We believe that despite its importance to children, the field of motor development and physical therapy has remained disappointingly neglected and we believe that we need to confirm that the current standards being used are appropriate and applicable to Egyptian children, and if not that a standardized scale which measures the normal development of Egyptian children be created and used.

The PDMS-2 is one of the most popular used scales all over the world, however it only examined children from western populations, and as such it is not clear if the populations used to create the normative values are broadly applicable to those of all children, and in particular those from Egypt. The need to establish a fine motor scale that is representative to the fine motor development in Egyptian children is needed. There has been no study conducted to check the applicability of the PDMS-2 in Egypt. Thus, the regional relevance of the PDMS- 2 must be examined, specifically when scores are used to determine whether a child is "normal" or delayed. Therefore; it was very important to establish norms for the Egyptian children in fine motor developmental skills to find a way of assessment that might be more clinically relevant for Egyptian children.

\section{Methods}

\section{Sample}

An estimated cluster sample of three governorates from the total governorates represented in the Greater Cairo Area, Egypt was studied; reaching a total of 195 participants. Children of either gender with ages from 36 to 42 months were included. Children were excluded if they failed the screening test (scoring a value of $<80 \%$ on the Portage Scale), or had active medical conditions or were uncooperative on 3 trials.

\section{Instruments}

The Portage checklist has been introduced successfully into countries across the world and translated into different languages, Arabic version. It focuses on the role of daily contact with the child recognizing the critical importance of the interactions taking place between parent/care and child in promoting the early development of the young child. The Portage kit is an Activity Card File that consists of 580 developmentally sequenced questions from birth to age nine, it contain five domains: Socialization, SelfHelp, Language, Cognition, and Motor.

PDMS-2 norm-referenced and standardized motor skill test that consists of 6 subscales of which the scores from 4 subscales that combined to give a gross motor quotient (GMQ) and 2 subscales combined to give a fine motor quotient (FMQ). For each item, the manual describes the child's beginning position, the materials needed, and directions for administering the item and the criterion for scoring. The criterion for scoring each response is written in a behavioral objective format which specifies the number of trials permitted or the time allotted. Each response is scored on a 3-point scale $\left(0_{\text {_ }}\right.$ unsuccessful, $1_{\text {_ }}$ clear resemblance to item criterion but criterion not fully met, 2 _ successful performances, criterion met). The administration of both Gross Motor Scale and Fine Motor Scale takes approximately 45 to 60 minutes [5].

\section{Procedure}

Subjects were recruited for the study from nursery schools and play schools in Egypt. Screening was done by administering the Portage Checklist as per the guidelines given in the scale. The child was included in the study if they achieved a score of at least $80 \%$ according to the portage motor checklist.

The PDMS-2 was then administered according to guidelines provided in the manual, using the floor and ceiling rules to minimize the administration time. The data were recorded in the examiner record booklets. The obtained raw scores for visual motor integration subtest of the scale were converted to age equivalent, percentile, and standard scores. All the values were recorded on the summary score sheet. The standard scores and the quotients were converted to z-scores for analysis were used for comparison with the normative mean values in the PDMS-2 manual.

\section{Data Analysis}

Data analysis was done using SPSS ver.14.0 and Arcos software packages. The mean and standard deviations were calculated for the raw scores, standard scores, for age group (36-42 months). The $\mathrm{z}$-scores for the standard scores for fine motor scale were calculated and compared with the normative z-scores provided in the manual.

\section{Results}

The three groups of Egyptian children from Greater Cairo Area (Cairo, Giza, and Kaliobia) were homogenous in mean age. Mean 


\section{Academic Journal of Pediatrics \& Neonatology}

ages of Greater Cairo Area were calculated in one group. The mean age (in months), the mean, and standard deviations for the raw scores of selected items for both boys and girls were according to the child' chronological age (36 to 42 months) presented in Table1.

Table 1: The comparison between boys and girls mean score in the Greater Cairo Area per age group (36 to 42 months) for the selected items.

\begin{tabular}{|c|c|c|c|c|c|c|c|c|}
\hline \multirow[t]{2}{*}{ Items } & \multirow{2}{*}{$\begin{array}{l}\text { Age(months) } \\
\text { Mean } \pm \text { S.D }\end{array}$} & \multicolumn{2}{|c|}{ Boys $(n=71)$} & \multicolumn{2}{|c|}{ Girls $(n=124)$} & \multirow[t]{2}{*}{ t-Value } & \multirow[t]{2}{*}{ P -Value } & \multirow[t]{2}{*}{ Ind. } \\
\hline & & Mean Score & S.D & Mean Score & S.D & & & \\
\hline $22-\mathrm{G}$ & $34.65+1.35$ & 47.17 & 1.37 & 46.31 & 1.23 & 2.487 & 0.016 & $S^{*}$ \\
\hline 23- G & $40.03+1.72$ & 48.43 & 1.77 & 47.77 & 1.66 & 1.445 & 0.154 & NS \\
\hline $57-\mathrm{V}$ & $37.98+1.79$ & 117.6 & 1.58 & 116.57 & 1.81 & 2.231 & 0.03 & $\mathrm{~S}^{*}$ \\
\hline $58-\mathrm{V}$ & $39.58+1.25$ & 117.83 & 1.27 & 117.42 & 1.24 & 1.182 & 0.242 & NS \\
\hline $59-\mathrm{V}$ & $38.82+1.45$ & 121.26 & 1.09 & 120.54 & 1.59 & 1.882 & 0.065 & NS \\
\hline $60-\mathrm{V}$ & $41.94+1.46$ & 122.22 & 1.27 & 121.77 & 1.55 & 1.144 & 0.257 & NS \\
\hline $61-\mathrm{V}$ & $41.18+1.62$ & 125.3 & 1.55 & 125.11 & 1.69 & 0.432 & 0.667 & NS \\
\hline $62-\mathrm{V}$ & $40.58+1.14$ & 125.83 & 1.15 & 125.11 & 1.12 & 1.307 & 0.196 & NS \\
\hline $63-V$ & $41.91+1.34$ & 128.47 & 1.41 & 127.54 & 1.17 & 2.742 & 0.008 & $\mathrm{HS}^{* *}$ \\
\hline
\end{tabular}

The measurable items for this age were two items of grasping subtest of PDMS; 22- G: Grasping marker, 23- G: Unbuttoning button and seven items of visual motor integration subtest; $57-\mathrm{V}$ : Cutting paper with blunt scissor, 58-V: Lacing string into 3 holes, 59-V: Copying cross, 60-V: cutting on the line drawn, 61-V: Copying cross in the middle, 62-V: Dropping 10 food pellets, and 63-V: Tracing line drawn, With taken into consideration the basal and the ceiling level of scoring according to the Illustrated Guide for Administering and Scoring of the PDMS-2 Items.

The sample of this age includes 195 children, 71 of them are boys and 124 are girls and we report here the statistical analysis of all data collected. Descriptive analysis for the mean values of Egyptian children development during this study for this age was shown to have a significant statistical difference between boy and girl groups in 22-G, 57-V, and it highly significant in 63-V items.

The statistical analysis of the Z-score and percentile rank of the standard scores for this age group indicated that there was a significant difference between the three groups of Egyptian children from greater Cairo area (Cairo, Giza, and Kaliobia) and the normative sample in favor of Egyptian children in grasping items and in favor of European sample in visual motor integration items; were presented in Table 2 and shown in Figure 1.

Table 2: Comparison between the standardized score (Z) for Egyptian and European normative sample per age group (36 to 42 months) for the selected items.

\begin{tabular}{|c|c|c|c|c|c|c|c|c|c|}
\hline \multirow{2}{*}{ Items } & \multirow{2}{*}{$\begin{array}{l}\text { Age group } \\
\text { (months) In } \\
\text { PDMS }\end{array}$} & \multicolumn{2}{|c|}{ Giza $\quad(n=87)$} & \multicolumn{2}{|c|}{ Cairo $(n=58)$} & \multicolumn{2}{|c|}{ Kaliobia $(n=50)$} & \multicolumn{2}{|c|}{ Normative sample } \\
\hline & & Z-score & P.R & Z-score & P.R & Z-score & P.R & Z- score & P.R \\
\hline $22-\mathrm{G}$ & $41-42$ & 1.828 & 96.62 & 1.743 & 95.94 & 1.875 & 96.96 & -3.73 & 1 \\
\hline $23-G$ & $41-42$ & 1.089 & 86.2 & 1.138 & 87.25 & 0.543 & 70.64 & -3.6 & 1 \\
\hline $57-V$ & $37-38$ & -0.085 & 46.58 & 0.009 & 50.38 & -0.181 & 42.81 & 0.93 & 82 \\
\hline $58-\mathrm{V}$ & $39-40$ & -0.48 & 31.53 & 0.329 & 62.9 & -0.706 & 24 & 1.07 & 86 \\
\hline $59-\mathrm{V}$ & $39-40$ & 0.037 & 51.5 & 0.807 & 79.02 & -0.186 & 42.59 & 1.2 & 89 \\
\hline $60-\mathrm{V}$ & $41-42$ & -0.093 & 46.29 & 0.035 & 51.42 & -0.17 & 43.22 & 1.33 & 91 \\
\hline $61-\mathrm{V}$ & $41-42$ & 0.415 & 66.12 & 0.498 & 69.08 & 0.253 & 60.02 & 1.47 & 93 \\
\hline $62-\mathrm{V}$ & $41-42$ & 0.299 & 61.76 & 1.24 & 89.26 & 0.031 & 51.25 & 1.6 & 95 \\
\hline $63-\mathrm{V}$ & $41-42$ & 0.059 & 52.38 & 0.064 & 52.56 & -0.254 & 39.94 & 1.73 & 96 \\
\hline
\end{tabular}

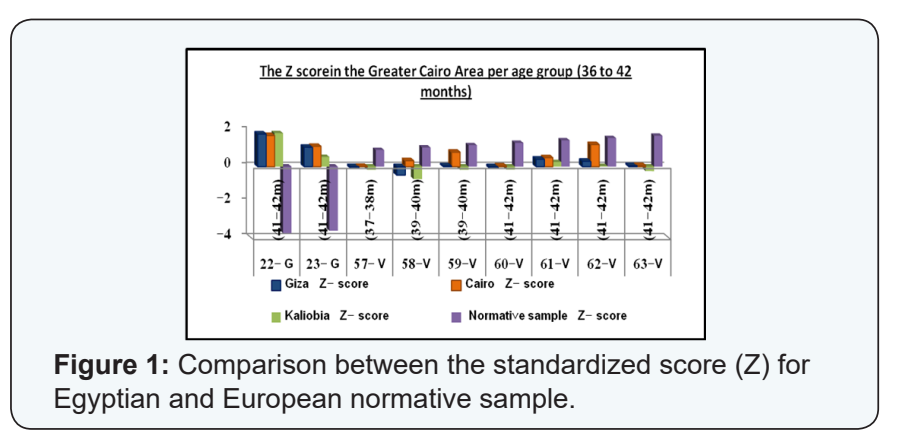

\section{Discussion}

Development is influenced by heredity and environment. One of the environmental factors that affect development is culture which may affect performance of a child on a developmental test that does not reflect typical cultural experiences for a specific population. Because differences in motor development have been found among various ethnic groups, the cultural relevance of standardized developmental tests must be examined [6]. 
Uses of scales that are developed for western populations are not always applicable to all the diverse cultural groups and regions of the world, so that the cultural and regional relevance of a scale must be checked before using. Such a project is especially important because these tests are used to determine whether a child is developing typically or is in some way delayed, requiring special services [7].

Motor assessments designed for children of the dominant or mainstream culture are not always appropriate for those from diverse ethnic backgrounds. This study was undertaken to compare the scores of children from one ethnic group with the scores of the children on whom the test was normed. It was observed that there were significant differences in the scores of the children from our sample, compared with the normative data given in the manual of PDMS-2. It indicates that cultural differences could significantly affect the scores of the children on the scale [8].

The ages of the study population ranged from 36 to 42 months. It contains two items of grasping subtest of PDMS; Grasping marker which develop earlier in Egyptian children around 34 months than in the normative western-derived sample around 41 months and Unbuttoning button which develops in Egyptian children around 40 months and in the normative sample around 41 months, along with seven items of visual motor integration subtest; Cutting paper with blunt scissor which develops in Egyptian children around 37 months as in the normative sample, Lacing string into 3 holes which develops in Egyptian children around 39 months as in the normative sample, Copying cross which develops in Egyptian children around 39 months as in the normative sample, cutting on the line drawn, Copying cross in the middle, Dropping 10 food pellets, and Tracing line drawn which develops in Egyptian children around 41 months as in the normative sample.

The grasping and the visual motor integration skills that were to have a highly significant difference in the mean standardized (Z) score of the third group, in favor of Egyptian children for grasping items and in favor of European children for visual motor integration items. Growth potential in preschool children is similar across developing countries, and stunting in early childhood is caused by poor nutrition and infection rather than by genetic or geographical differences. Patterns of growth retardation are also similar across countries. Faltering begins in utero or soon after birth, is pronounced in the first 12-18 months, and could continue to around 40 months, after which it levels off [9].

The higher performance in grasping subtest is seen from the age of 36 months and is maintained until the age of 54 months, reaffirms the findings of another study that suggested that the increase in maximal isometric grip strength during childhood and in preadolescence stages has two components; The first is muscle growth, which takes a gender-specific course during puberty, indicating that it is influenced by hormonal changes. The second increase in grip strength per muscle cross sectional area (CSA) [10].
While the lower performance of visual motor integration subtest, seen from the age of 36 months, could be better understood applying the findings from another study which reported that the hand represents an excellent model in which to study one of the most intriguing issues in motor control: simultaneous control of a large number of mechanical degrees of freedom. The complex apparatus of the human hand is used both to grasp objects of all shapes and sizes through the linked action of multiple digits and to perform the skilled, individuated finger movements needed for a large variety of creative and practical endeavors, such as handwriting, painting, sculpting, and playing a musical instrument [11].

\section{Conclusion}

In general, the findings reported here confirm several significant differences between the scores of children 36 to 42 months from the Greater Cairo Area, Egypt, and those of the western-generated normative sample used as a standard or normative comparator in the currently available version of the PDMS-2.

It is not always practical to develop assessment tools which are culturally sensitive across the totality of regions and environments where they may be needed and used, but it is necessary to evaluate the cultural and geographical differences that may be evident for standardized tests for a particular region and ethnic group, especially when these instruments are being used to assess areas of motor development of Egyptian children and serve as a means of access to important and needed therapeutic resources. We may be unknowingly limiting access to children who would benefit from therapeutic help, and providing to others who are less likely to need or benefit from it. Applicable standards for motor development that are relevant to Egyptian children are needed.

\section{Acknowledgment}

Thank you to Prof. Dr. Faten Abdelazeim and Prof. Dr. Amany Mousa for their review of the manuscript. The authors thank the children and the families who participated in this study; the staff of the various nursery schools and baby class members for assistance in recruitment and use of their facilities for the support of this study.

\section{References}

1. Cook SA, Woollacott MH (2004) Postural control in: Motor control theory and practical applications $2^{\text {nd }}(\mathrm{edn})$ Lippincott Williams and Wilkins, Philadephia, USA, pp: 163-217.

2. Rakha MA, Abdelmoneim AN, Farhoud $S$, Pièche $S$, Cousens $S$, et al. (2013) Does Implementation of IMCI strategy have an impact on child mortality? A retrospective analysis of routine data from Egypt. BM] $3(1): 1-9$.

3. Bart O, Hajami D, Bar-Haim Y (2007) Predicting school adjustment from motor abilities in kindergarten. Infant \& Child Development 16(6): 597-615.

4. Phillips D (2012) Concurrent validity and responsiveness of the Peabody Developmental Motor Scales $2^{\text {nd }}(e d n)$ in infants and children with Pompe disease undergoing enzyme replacement therapy. pp: 
$1-20$.

5. https://www.aceredu.au/documents/PDMS-2DetailedReportSample. pdf

6. Cintas HL (1995) Cross-cultural similarities and differences in development and the impact of parental expectations on motor behavior. Pediatr Phys Ther 7(3): 103-111.

7. Krefting L (2009) The culture concept in the everyday practice of occupational and physical therapy. Phys Occup Ther Pediatr 11(4): 1-16.

8. Crowe TK, McClain C, Provost B (1999) Motor development of Native American children on the Peabody Developmental Motor Scales. Am J Occup Ther 53(5): 514-518
9. WHO Multicentre Growth Reference Study Group (2006) Assessment of differences in linear growth among populations in the WHO Multicenter Growth Reference Study. Acta Paediatr Suppl 450: 56-65.

10. Smith T, Smith S, Martin M, Henry R, Weeks S, et al. (2009) Grip strength in relation to overall strength and functional capacity in very old and oldest old females. 24(24): 63-78.

11. Winges SA, Weber DJ, Santello M (2003) The role of vision on hand preshaping during reach to grasp. Exp Brain Res 152(4): 489-498.
Your next submission with JuniperPublishers will reach you the below assets

- Quality Editorial service

- Swift Peer Review

- Reprints availability

- E-prints Service

- Manuscript Podcast for convenient understanding

- Global attainment for your research

- Manuscript accessibility in different formats ( Pdf, E-pub, Full Text, Audio)

- Unceasing customer service

Track the below URL for one-step submission http://juniperpublishers.com/online-submission.php 